\title{
Nearest-neighbor parameters for 7-deaza-adenosine-uridine base pairs in RNA duplexes
}

\author{
KATHERINE E. RICHARDSON and BRENT M. ZNOSKO \\ Department of Chemistry, Saint Louis University, Saint Louis, Missouri 63103, USA
}

\begin{abstract}
One of the major limitations in RNA structure prediction is the lack of information about the effect of nonstandard nucleotides on stability. The nonstandard nucleotide 7-deaza-adenosine (7DA) is a naturally occurring analog of adenosine that has been studied for medicinal purposes and is commonly referred to as tubercidin. In 7DA, the nitrogen in the 7 position of adenosine is replaced by a carbon. Differences in RNA duplex stability due to the removal of this nitrogen can be attributed to a possible change in hydration and a difference in base stacking interactions resulting from changes in the electrostatics of the ring. In order to determine how 7DA affects the stability of RNA, optical melting experiments were conducted on RNA duplexes that contain either internal or terminal $7 \mathrm{DA} \cdot \mathrm{U}$ pairs with all possible nearest-neighbor combinations. On average, duplexes containing 7DA.U pairs are 0.43 and $0.07 \mathrm{kcal} / \mathrm{mol}$ less stable than what is predicted for the same duplex containing internal and terminal A-U pairs, respectively. Thermodynamic parameters for all nearest-neighbor combinations of 7DA-U pairs were derived from the data. These parameters can be used to more accurately predict the secondary structure and stability of RNA duplexes containing $7 \mathrm{DA} \cdot \mathrm{U}$ pairs.
\end{abstract}

Keywords: 7-deaza-adenosine; nearest-neighbor parameters; optical melting; nonstandard nucleotide

\section{INTRODUCTION}

An abundance of RNA primary sequence information has been made available from a variety of sequencing projects. However, the secondary and tertiary structures of RNA must be studied to better understand the function of RNA, how it interacts with other biomolecules, and how it can be targeted by potential therapeutics. Recent efforts (Mathews et al. 1999; Shi et al. 2014) have helped to understand and predict secondary structure from sequence, but one of the noteworthy limitations in RNA structure prediction is the lack of information about the effect of nonstandard nucleotides on stability.

In addition to the standard nucleotides, RNA contains a wide variety of nonstandard, or modified, bases, allowing it to play a part in many different biological roles. The RNA Modification Database currently contains information on 112 post-transcriptional modifications to RNA that have been noted in archaea, bacteria, and eukarya (Cantara et al. 2011). The roles that these modifications play in biological systems are beginning to be elucidated (Cantara et al. 2011); however, our present knowledge of RNA nucleotide modifications and the effects of modification are still limited.

Recent studies with RNA duplexes containing the nonstandard nucleotides inosine (I) and pseudouridine ( $\Psi$ )

Corresponding author: znoskob@slu.edu

Article published online ahead of print. Article and publication date are at http://www.rnajournal.org/cgi/doi/10.1261/rna.055277.115. have reported noteworthy changes in RNA thermodynamic stability after conversion from the corresponding standard nucleotides (Wright et al. 2007; Hudson et al. 2013). When an adenosine (A) is converted to an I as a result of oxidative deamination by an enzyme family known as adenosine deaminases that act on RNA (ADARs), numerous changes take place (Fig. 1A,B). An amino group of $\mathrm{A}$ is replaced with an oxygen, converting a hydrogen bond donor to a hydrogen bond acceptor. As a result of this functional group replacement, a $\mathrm{C}=\mathrm{N}$ double bond in the 6-membered ring is converted to a single bond, and the single bond between the carbon and amino group of $\mathrm{A}$ is replaced with a $\mathrm{C}=\mathrm{O}$ double bond. Additionally, the N3 of A is converted to $\mathrm{NH}$ on $\mathrm{I}$, changing a hydrogen bond acceptor to a hydrogen bond donor. A shifted conformation, relative to the A-U conformation, is necessary to maintain two hydrogen bonds between $I$ and $U$, which would alter the stacking of this hydrogen-bonded pair with the neighboring base pairs. Overall, the conversion of an A-U pair to an $\mathrm{I} \cdot \mathrm{U}$ pair yields the same number of hydrogen bonds between the WatsonCrick faces with a shifted conformation; however, a duplex

(C) 2016 Richardson and Znosko This article is distributed exclusively by the RNA Society for the first 12 months after the full-issue publication date (see http://rnajournal.cshlp.org/site/misc/terms.xhtml). After 12 months, it is available under a Creative Commons License (Attribution-NonCommercial 4.0 International), as described at http://creativecommons.org/licenses/by$\mathrm{nc} / 4.0 \%$. 

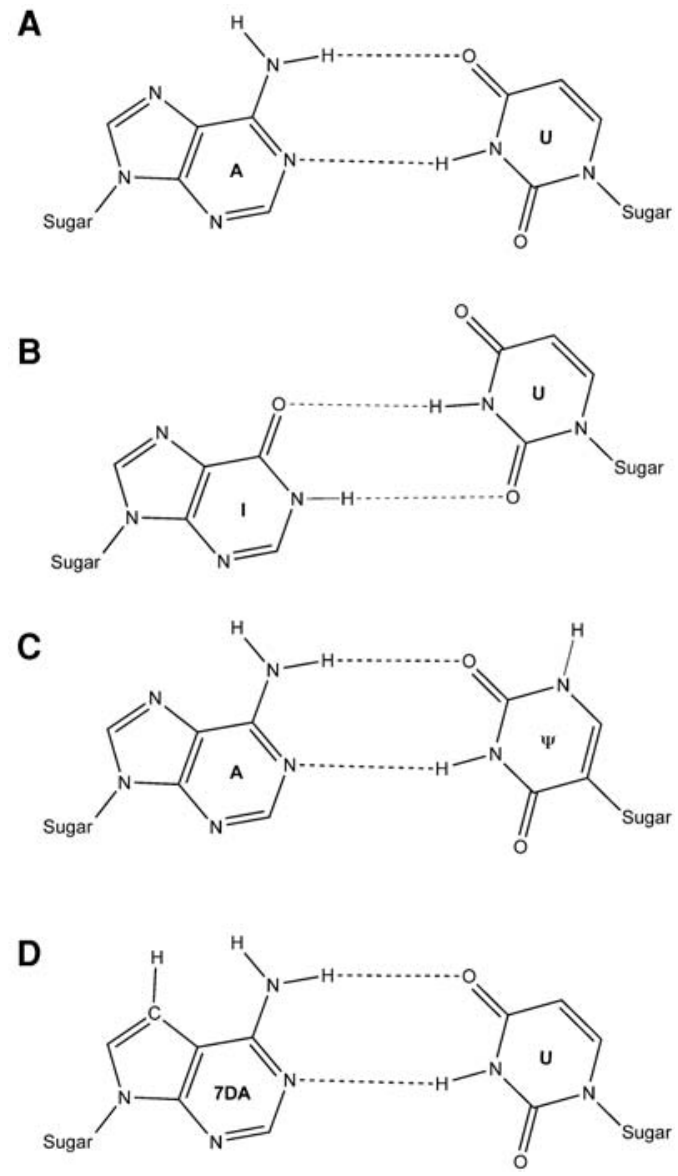

FIGURE 1. Likely conformation of a Watson-Crick A-U base pair $(A)$, $\mathrm{I} \cdot \mathrm{U}$ pair $(B), \mathrm{A} \cdot \Psi$ pair $(C)$, and $7 \mathrm{DA} \cdot \mathrm{U}$ pair $(D)$.

containing an internal I.U pair is, on average, $2.3 \mathrm{kcal} / \mathrm{mol}$ less stable than the same duplex with an $\mathrm{A}-\mathrm{U}$ pair (Wright et al. 2007).

When a uridine is converted to a pseudouridine by the enzyme pseudouridine synthase, the base is essentially detached from the sugar, rotated, and reattached at the carbon- 5 position (Charette and Gray 2000). The conversion of a U-A pair to a $\Psi \cdot A$ pair also does not change the number of hydrogen bonds between the Watson-Crick faces but introduces a new hydrogen bond donor into the major groove through isomerization (Fig. 1A,C). In this instance, the number and types of atoms remain the same and no base shifting is required to hydrogen bond with $\mathrm{A}$; however, a rearrangement occurs in which the nitrogen on the sugar face is moved to the Hoogsteen face, and the double bond is moved within the ring, which likely alters the stacking interactions of this base pair with the neighboring base pairs. Hudson et al. (2013) reported that a duplex containing an internal $\Psi \cdot A$ pair is, on average, $1.7 \mathrm{kcal} / \mathrm{mol}$ more stable than the duplex with the corresponding U-A pair. With the recent insight that the modifications I and $\Psi$ yield significant changes in stability, it would be beneficial to better understand how small changes to standard base pairs change the stability of RNA du- plexes. The free energy changes and the roles of particular functional groups should be easier to interpret if there are fewer changes between the standard and modified nucleotides.

Of the many modified nucleotides found in RNA, 7-deazaadenosine (7DA) introduces a small change to the base structure and has been of substantial interest to the scientific community (Anzai et al. 1957; Acs et al. 1964; Owen and Smith 1964; Bloch et al. 1967; Olsen et al. 2004; Vittori et al. 2006; Dominguez-Martin et al. 2013; Kurogi et al. 2014). 7DA is an analog of adenosine, in which the nitrogen in the 7 position of adenosine (N7) is replaced by a carbon (Fig. 1A,D). This modification does not change the Watson-Crick face, so the number of hydrogen bonds formed with $\mathrm{U}$ remains the same, and no shifting occurs. On the sugar edge, the number and types of atoms and the types of covalent bonds also remain the same. The primary changes resulting from the removal of this nitrogen are a potential hydrogen bond acceptor on the Hoogsteen face of A is lost, and the electrostatics of the ring likely change, which could have an impact on the base stacking.

7DA has been found naturally in the bacteria Streptomyces tubercidicus and the marine sponge Caulospongia biflabellata (Biabani et al. 2002). It has been studied for medicinal purposes as an antibiotic (Anzai et al. 1957; Bloch et al. 1967), antiviral (Olsen et al. 2004; Vittori et al. 2006), and anticancer (Owen and Smith 1964) agent due to its cytotoxicity and is commonly referred to as tubercidin. Studies have shown that when introduced into mammalian cells, this analog is incorporated into DNA and RNA (Acs et al. 1964). The effects of 7DA on many cellular functions, such as the inhibition of nuclear speckle formation (Kurogi et al. 2014), have also been investigated. When substituted for $A$, this analog can be used to better understand the importance of the N7 position of adenine when it behaves as a ligand (Dominguez-Martin et al. 2013). In a computational study of the incorporation of tubercidin into RNA during transcription, the stacking ability of 7DA was studied, and the authors found that it was more likely to be incorporated near a $\mathrm{G}$ or $\mathrm{C}$ compared to an $\mathrm{A}$ or $\mathrm{U}$ due to a more favorable stacking energy (Ojha and Sanyal 1991).

In addition to being important due to its biological role, studies with 7DA can also shed light on the role of N7 in stabilizing A-U pairs. Since the Watson-Crick face of 7DA is identical to its analog $\mathrm{A}$, the number of hydrogen bonds between Watson-Crick faces will remain the same. Differences in stability may be attributed to a difference in base stacking, as the substitution of a carbon for N7 reduces polarity and may change the $\pi$ stacking interactions with adjacent bases. Additionally, a possible difference in hydration due to the loss of a hydrogen bond acceptor at the N7 position (in the major groove) may contribute to a difference in stability. Since this nonstandard nucleotide has many applications, it would be beneficial to better understand and be able to quickly predict how the stability and secondary structure of an RNA sequence may be affected by its incorporation. In this study, we explored how 7DA affects the stability of 
RNA Watson-Crick duplexes by using optical melting experiments to derive nearest-neighbor parameters for $7 \mathrm{DA} \cdot \mathrm{U}$ pairs, which are reported herein. The stabilities of the studied duplexes were compared to the stabilities of the same duplexes containing A-U pairs, as predicted by the nearest-neighbor model (Xia et al. 1998). Interestingly, we discovered that 7DA.U pairs usually resulted in a loss of stability compared to duplexes with the corresponding A-U pairs, with the most variability occurring in duplexes with terminal 7DA.U pairs. On average, duplexes containing internal and terminal 7DA. $\mathrm{U}$ pairs are 0.43 and $0.07 \mathrm{kcal} / \mathrm{mol}$ less stable than what is predicted for the same duplex containing internal and terminal A-U pairs, respectively.

\section{RESULTS}

\section{Thermodynamic parameters}

The thermodynamic parameters of duplex formation derived from van't Hoff plots and melt curve fits are shown in Table 1 . The model used to derive the thermodynamic parameters assumes a two-state transition during melting. Since all of the enthalpy parameters derived from the melt curve fits are within 15\% of the enthalpy values of the van't Hoff plots, we can assume a two-state transition (Schroeder and Turner 2009).

\section{Comparison of $7 \mathrm{DA} \cdot \mathrm{U}$ experimental free energies to $\mathrm{A}-\mathrm{U}$ predicted free energies}

On average, duplexes containing 7DA.U pairs are 0.43 and $0.07 \mathrm{kcal} / \mathrm{mol}$ less stable than what is predicted for the same duplex containing internal and terminal A-U pairs, respectively (Table 2); however, a substantial range was observed. A duplex containing a 7DA.U pair was measured from $1.21 \mathrm{kcal} / \mathrm{mol}$ more stable to $0.91 \mathrm{kcal} / \mathrm{mol}$ less stable than what is predicted for a duplex containing the corresponding A-U pair. According to Schroeder and Turner, a free energy difference of $0.5 \mathrm{kcal} / \mathrm{mol}$ can be considered a significant difference when comparing the free energies of two RNA duplexes (2009). Twelve out of the 24 duplexes containing 7DA. $U$ pairs had a significant difference in free energy compared to what is predicted for the duplex containing the corresponding A-U pair. There is no obvious sequence pattern between the 7DA.U duplexes that are significantly different from those that are not. Similar calculations and comparisons for enthalpies and entropies can be viewed in Supplemental Tables S1 and S2.

\section{Thermodynamic contribution of $7 \mathrm{DA} \cdot \mathrm{U}$ base pairs and derivation of nearest-neighbor parameters}

The calculated thermodynamic contributions of 7DA.U pairs can be viewed in the Supplemental Table S3. As described in Materials and Methods, linearly independent nearest-neigh- bor parameters were derived for 7DA.U pairs (Table 3 ). The average free energy contribution of 7DA.U nearest neighbors is $-1.42 \mathrm{kcal} / \mathrm{mol}$ compared to A-U nearest neighbors which contribute on average $-1.73 \mathrm{kcal} / \mathrm{mol}$ (Xia et al. 1998). All of the generated 7DA.U nearest-neighbor free energy contributions are less stabilizing than their A-U equivalents except for the ${ }_{\mathrm{UA}}^{7 \mathrm{U}}$ term, which is $0.36 \mathrm{kcal} / \mathrm{mol}$ more stabilizing than the AU term (Xia et al. 1998). The terminal 7DA.U penalty of $0.31 \mathrm{kcal} / \mathrm{mol}$ is less destabilizing than the $0.45 \mathrm{kcal} / \mathrm{mol}$ penalty of terminal A-U pairs (Xia et al. 1998).

The new 7DA.U nearest-neighbor parameters were used with the previously determined parameters for standard Watson-Crick pairs (Xia et al. 1998) to calculate the predicted stabilities of the studied duplexes (Table 1). The average deviations between the predicted and experimental values were $3.2 \%, 2.7 \%$, and $3.2 \%$ for $\Delta G^{\circ}{ }_{37}, \Delta H^{\circ}$, and $\Delta S^{\circ}$, respectively. These values are comparable to those previously reported for standard Watson-Crick pairs (3.2\%, 6.0\%, $6.8 \%$, respectively) (Xia et al. 1998), inosine-uridine base pairs (5.1\%, 4.6\%, 5.1\%, respectively) (Wright et al. 2007), and pseudouridine-adenosine base pairs (1.7\%, 6.7\%, 8.0\%, respectively) (Hudson et al. 2013).

\section{DISCUSSION}

\section{Duplex formation and two-state melts}

All van't Hoff plots showed a linear relationship between $T_{\mathrm{M}^{-1}}$ and $\log \left(C_{\mathrm{T}} / 4\right)$, suggesting that duplex formation occurred as opposed to unimolecular folding. A single, sharp transition indicated the presence of a single species in solution. The agreement within $15 \%$ of all enthalpy values derived from the melt curve fits and van't Hoff plots provides evidence of a two-state transition (Schroeder and Turner 2009).

\section{Comparison of thermodynamics and nearest-neighbor parameters of $7 \mathrm{DA} \cdot \mathrm{U}$ pairs to $\mathrm{A}-\mathrm{U}$ pairs}

The nearest-neighbor parameters for 7DA.U pairs are shown in Table 3. Similar to standard Watson-Crick A-U pairs (Xia et al. 1998), all combinations of 7DA.U nearest neighbors contribute a negative term to total $\Delta G^{\circ}{ }_{37}$, total $\Delta S^{\circ}$, and total $\Delta H^{\circ}$ values. The stabilizing influence of neighboring Watson-Crick pairs on 7DA.U pairs follows the trends for the $5^{\prime}$ and $3^{\prime}$ base pairs: ${ }_{\mathrm{GU}}^{\mathrm{C} 7}>{ }_{\mathrm{CU}}^{\mathrm{G} 7}>{ }_{\mathrm{AU}}^{\mathrm{U} 7}>{ }_{\mathrm{UU}}^{\mathrm{A} 7}$ and ${ }_{\mathrm{UG}}^{7 \mathrm{C}}>{ }_{\mathrm{UC}}^{7 \mathrm{G}}>{ }_{\mathrm{UA}}^{7 \mathrm{U}}>\frac{7 \mathrm{~A}}{\mathrm{UU}}$, respectively. These observed trends are similar to the trend for favorable stacking energy values of bases adjacent to 7DA predicted computationally, in which $\mathrm{G} \geq \mathrm{C}>\mathrm{U}>\mathrm{A}$ (Ojha and Sanyal 1991). The stabilizing influence of neighboring Watson-Crick pairs on A-U pairs follows similar trends for $5^{\prime}$ and $3^{\prime}$ base pairs: $\mathrm{CU}_{\mathrm{CU}}^{\mathrm{GA}}>{ }_{\mathrm{GU}}^{\mathrm{CA}}>{ }_{\mathrm{AU}}^{\mathrm{UA}}>\underset{\mathrm{UU}}{\mathrm{AA}}$ and ${ }_{\mathrm{UG}}^{\mathrm{AC}}>\underset{\mathrm{UC}}{\mathrm{AG}}>\frac{\mathrm{AU}}{\mathrm{AA}}>\underset{\mathrm{UU}}{\mathrm{AA}}$, respectively 


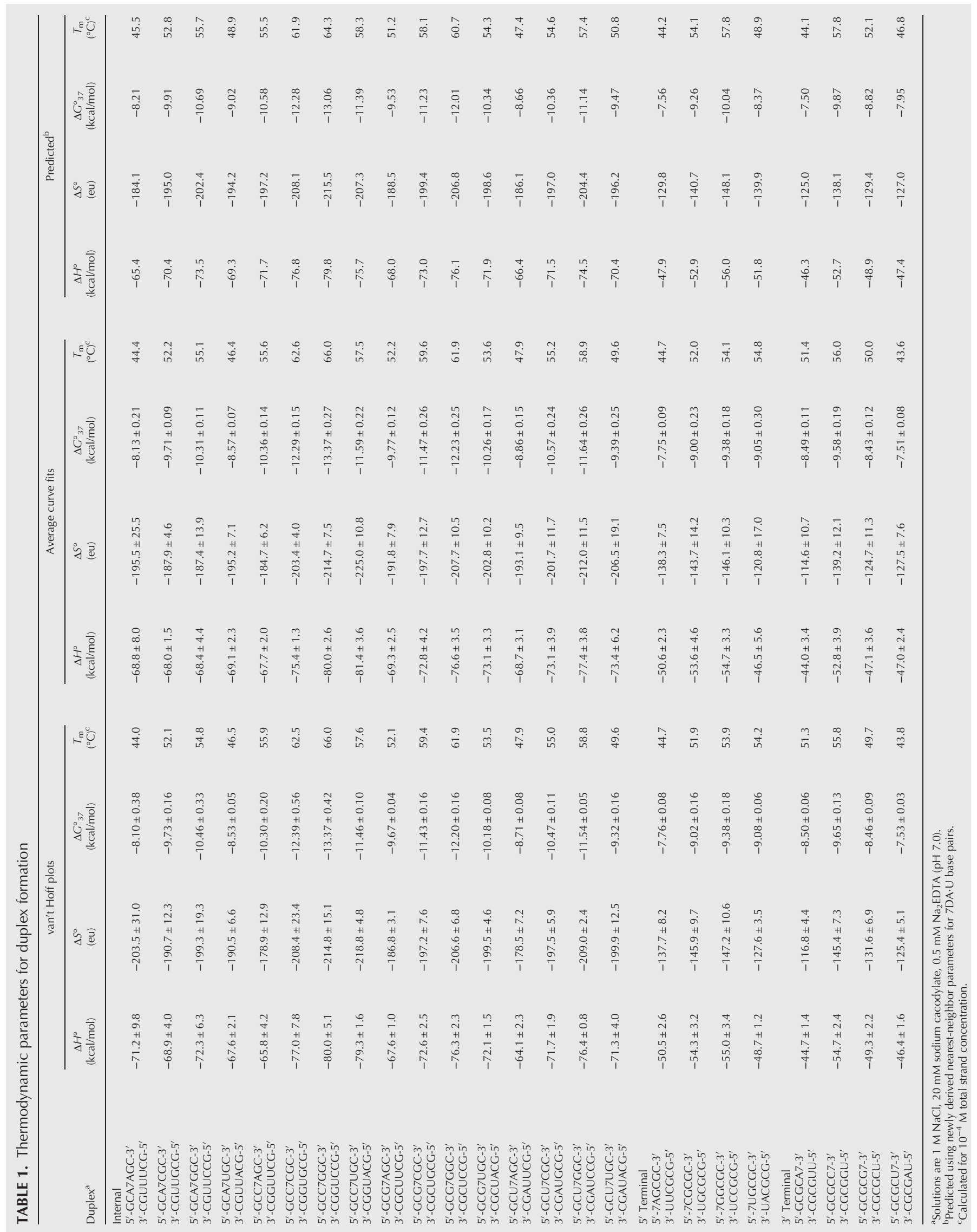


TABLE 2. Comparison of free energy of duplex formation for duplexes containing 7DA.U pairs with predicted free energy for corresponding A-U duplexes

\begin{tabular}{|c|c|c|c|}
\hline Duplex & $\begin{array}{c}\text { 7DA.U } \\
(\mathrm{kcal} / \mathrm{mol})^{\mathrm{a}}\end{array}$ & $\begin{array}{c}\mathrm{NN} \mathrm{A-U} \\
(\mathrm{kcal} / \mathrm{mol})^{\mathrm{b}}\end{array}$ & $\begin{array}{c}\Delta \mathrm{A}-\mathrm{U} \\
(\mathrm{kcal} / \mathrm{mol})^{\mathrm{c}}\end{array}$ \\
\hline $\begin{array}{l}5^{\prime} \text {-GCA7AGC- } 3^{\prime} \\
3^{\prime} \text {-CGUUUCG-5 }\end{array}$ & -8.10 & -8.80 & -0.70 \\
\hline $\begin{array}{l}5^{\prime} \text {-GCA7CGC- } 3^{\prime} \\
3^{\prime}-\text { CGUUGCG-5 }\end{array}$ & -9.73 & -10.39 & -0.66 \\
\hline $\begin{array}{l}5^{\prime} \text {-GCA7GGC-3' } \\
3^{\prime} \text {-CGUUCCG-5' }\end{array}$ & -10.46 & -11.13 & -0.67 \\
\hline $\begin{array}{l}5^{\prime} \text {-GCA7UGC-3' } \\
3^{\prime} \text {-CGUUACG-5' }\end{array}$ & -8.53 & -9.00 & -0.47 \\
\hline $\begin{array}{l}5^{\prime} \text {-GCC7AGC- } 3^{\prime} \\
3^{\prime} \text {-CGGUUCG-5 }\end{array}$ & -10.30 & -11.13 & -0.83 \\
\hline $\begin{array}{l}5^{\prime} \text {-GCC7CGC-3' } \\
3^{\prime} \text {-CGGUGCG-5' }\end{array}$ & -12.39 & -12.72 & -0.33 \\
\hline $\begin{array}{l}5^{\prime}-\text { GCC7GGC-3' } \\
3^{\prime}-\text { CGGUCCG-5' }\end{array}$ & -13.37 & -13.46 & -0.09 \\
\hline $\begin{array}{l}5^{\prime} \text {-GCC7UGC-3' } \\
3^{\prime} \text {-CGGUACG-5' }\end{array}$ & -11.46 & -11.33 & 0.13 \\
\hline $\begin{array}{l}5^{\prime}-G C G 7 A G C-3^{\prime} \\
3^{\prime}-C G C \cup \cup C G-5^{\prime}\end{array}$ & -9.67 & -10.47 & -0.80 \\
\hline $\begin{array}{l}5^{\prime} \text {-GCG7CGC-3' } \\
3^{\prime} \text {-CGCUGCG-5' }\end{array}$ & -11.43 & -12.06 & -0.63 \\
\hline $\begin{array}{l}\text { 5'-GCG7GGC-3' } \\
3^{\prime} \text {-CGCUCCG-5' }\end{array}$ & -12.20 & -12.80 & -0.60 \\
\hline $\begin{array}{l}5^{\prime} \text {-GCG7UGC-3' } \\
3^{\prime} \text {-CGCUACG-5' }\end{array}$ & -10.18 & -10.67 & -0.49 \\
\hline 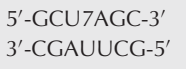 & -8.71 & -9.17 & -0.46 \\
\hline $\begin{array}{l}5^{\prime} \text {-GCU7CGC-3' } \\
3^{\prime}-\mathrm{CGA \cup GCG-5}\end{array}$ & -10.47 & -10.76 & -0.29 \\
\hline $\begin{array}{l}5^{\prime} \text {-GCU7GGC-3' } \\
3^{\prime} \text {-CGAUCCG-5' }\end{array}$ & -11.54 & -11.50 & 0.04 \\
\hline $\begin{array}{l}5^{\prime} \text {-GCU7UGC-3' } \\
3^{\prime} \text {-CGAUACG-5' } \\
\text { Average }\end{array}$ & -9.32 & -9.37 & $\begin{array}{l}-0.05 \\
-0.43\end{array}$ \\
\hline $\begin{array}{l}\text { 5'-7AGCGC-3' } \\
3^{\prime} \text {-UUCGCG-5' }\end{array}$ & -7.76 & -7.67 & 0.09 \\
\hline $\begin{array}{l}\text { 5'-7CGCGC-3' } \\
3^{\prime}-\text { UGCGCG-5' }\end{array}$ & -9.02 & -9.26 & -0.24 \\
\hline $\begin{array}{l}\text { 5'-7GGCGC-3' } \\
3^{\prime} \text {-UCCGCG-5' }\end{array}$ & -9.38 & -10.00 & -0.62 \\
\hline $\begin{array}{l}\text { 5'-7UGCGC-3' } \\
3^{\prime}-\text { UACGCG-5' } \\
\text { Average }\end{array}$ & -9.08 & -7.87 & $\begin{array}{l}1.21 \\
0.11\end{array}$ \\
\hline $\begin{array}{l}5^{\prime}-\text { GCGCA7-3' } \\
3^{\prime}-\text { CGCGUU-5' }\end{array}$ & -8.50 & -7.70 & 0.80 \\
\hline $\begin{array}{l}\text { 5'-GCGCC7--3' }^{\prime} \text {-GCGGU-5' } \\
3^{\prime} \text {-CGCGGU }\end{array}$ & -9.65 & -10.03 & -0.38 \\
\hline $\begin{array}{l}\text { 5'-GCGCG7-3' } \\
3^{\prime}-\text { CGCGCU-5' }\end{array}$ & -8.46 & -9.37 & -0.91 \\
\hline $\begin{array}{l}5^{\prime} \text {-GCGCU7-3' } \\
3^{\prime}-\text { CGCGAU-5' } \\
\text { Average }\end{array}$ & -7.53 & -8.07 & $\begin{array}{l}-0.54 \\
-0.26\end{array}$ \\
\hline Total average & & & -0.31 \\
\hline
\end{tabular}

${ }^{a}$ Measured value for $\Delta G^{\circ}{ }_{37}$ using van't Hoff plots.

${ }^{\mathrm{b}}$ Calculated using nearest-neighbor parameters by substituting $\mathrm{A}-\mathrm{U}$ for $7 \cdot \mathrm{U}$ base pairs (Xia et al. 1998). NN A-U values have a calculated uncertainty of $0.3 \mathrm{kcal} /$ mol.

'Difference between measured $\Delta G_{37}^{\circ}$ values and the predicted $\Delta G_{37}^{\circ}$ values using A- $U$ pairs in place of $7 . \cup$ pairs, where negative values indicate that duplexes containing $7 \cdot \mathrm{U}$ pairs are less stable than the corresponding duplexes containing $\mathrm{A}-\mathrm{U}$ pairs.
TABLE 3. Nearest-neighbor parameters for $7 D A \cdot U$ pairs

\begin{tabular}{|c|c|c|c|c|}
\hline $\begin{array}{l}\text { Nearest } \\
\text { neighbors }^{a}\end{array}$ & $\begin{array}{c}\# \\
\text { Occurrences }\end{array}$ & $\begin{array}{c}\Delta H^{\circ} \\
(\mathrm{kcal} / \mathrm{mol})^{\mathrm{b}}\end{array}$ & $\begin{array}{l}\Delta S^{\circ} \\
(\mathrm{eu})^{\mathrm{c}}\end{array}$ & $\begin{array}{c}\Delta G_{37}^{\circ} \\
(\mathrm{kcal} / \mathrm{mol})^{\mathrm{d}}\end{array}$ \\
\hline $\begin{array}{l}\text { A7 } \\
\text { UU }\end{array}$ & 5 & -8.4 & -25.1 & -0.59 \\
\hline $\begin{array}{l}\text { C7 } \\
\text { GU }\end{array}$ & 5 & -11.8 & -32.4 & -1.81 \\
\hline $\begin{array}{l}\text { G7 } \\
\text { CU }\end{array}$ & 5 & -10.8 & -29.7 & -1.66 \\
\hline $\begin{array}{l}\text { U7 } \\
\mathrm{AU}\end{array}$ & 5 & -9.4 & -26.9 & -1.07 \\
\hline $\begin{array}{l}7 \mathrm{~A} \\
\mathrm{UU}\end{array}$ & 5 & -9.9 & -29.7 & -0.68 \\
\hline $\begin{array}{l}7 C \\
\text { UG }\end{array}$ & 5 & -14.8 & -41.0 & -2.10 \\
\hline $\begin{array}{l}7 \mathrm{G} \\
\mathrm{UC}\end{array}$ & 5 & -15.1 & -42.4 & -1.98 \\
\hline $\begin{array}{l}7 U \\
U A\end{array}$ & 5 & -13.9 & -40.0 & -1.46 \\
\hline Terminal $7 \mathrm{U}$ & 8 & 9.3 & 29.0 & 0.31 \\
\hline
\end{tabular}

${ }^{a}$ For each nearest neighbor, the top sequence is written $5^{\prime}-3^{\prime}$ and the bottom is written $3^{\prime}-5^{\prime}$.

${ }^{\mathrm{b}}$ Standard error values for internal $\Delta H^{\circ}$ nearest-neighbor parameters are $\pm 1.6 \mathrm{kcal} / \mathrm{mol}$ and $\pm 1.1 \mathrm{kcal} / \mathrm{mol}$ for a terminal pair.

${ }^{\mathrm{c}}$ Standard error values for internal $\Delta S^{\circ}$ nearest-neighbor parameters are \pm 5.1 eu and \pm 3.6 eu for a terminal pair.

${ }^{d}$ Standard error values for internal $\Delta G_{37}^{\circ}$ nearest-neighbor parameters are $\pm 0.25 \mathrm{kcal} / \mathrm{mol}$ and $\pm 0.17 \mathrm{kcal} / \mathrm{mol}$ for a terminal pair.

(Xia et al. 1998). For both 7DA.U and A-U parameters, the extra hydrogen bond between a neighboring $\mathrm{G}-\mathrm{C}$ pair versus an A-U pair may explain why parameters with G-C neighbors are consistently more stable.

While the overall trends for 7DA.U nearest-neighbor parameters and A-U parameters are similar, the free energy contributions of 7DA.U nearest-neighbor combinations are less stabilizing than $\mathrm{A}-\mathrm{U}$ equivalents, with the exception of the ${ }_{\mathrm{UA}}^{7 \mathrm{U}}$ term, which is $0.36 \mathrm{kcal} / \mathrm{mol}$ more stabilizing than the ${ }_{\mathrm{UA}}^{\mathrm{AU}}$ term. The reasons for the differences in values and the overall average decrease in stability of duplexes containing 7DA.U pairs compared to A-U pairs could be due to a number of different sources. One possible source of destabilization is the loss of a hydrogen bond acceptor at the N7 position (Fig. 1). In a thermodynamic study with $\Psi$-A pairs, the addition of a hydrogen bond donor increased duplex stability (in comparison to the same duplex with a U-A pair) due to possible coordination with a water molecule (Hudson et al. 2013). Likewise, the N7 functional group located in the major groove of A-U pairs is available for interaction with the surrounding solvent. The loss of this functional group in 7DA.U pairs may cause a destabilizing change in hydration. Another possible source for the difference in stability is a change in the electrostatics of the ring system, which may result in less favorable stacking interactions. 
The atomic partial charges in the ring systems of 7DA and A show that the primary difference occurs around the 7 position, in which the concentrated electron density at the N7 position of $\mathrm{A}$ is distributed between $\mathrm{C} 5, \mathrm{C} 7$, and $\mathrm{C} 8$ in 7DA (Fig. 2). The electrostatics of the Watson-Crick face of adenosine are not substantially different from that of 7DA, therefore the strength of hydrogen bonding is expected to remain about the same. In a typical A-form helix, the 7 position overlaps with the $5^{\prime}$ adjacent base (Fig. $3 \mathrm{~A}, \mathrm{~B}$ ), but no direct overlap occurs at the 7 position with the $3^{\prime}$ adjacent base (Fig. 3C,D). Therefore, destabilization resulting from less favorable stacking interactions should be more pronounced when 7DA has a $5^{\prime}$ neighbor.

As expected, this difference in stacking can be seen when comparing the duplexes with terminal 7DA.U pairs to the same duplexes containing terminal A-U pairs. On average, duplexes with 7DA.U pairs on the $5^{\prime}$ terminal end (with 7DA at the $5^{\prime}$ end of the strand with no $5^{\prime}$ neighbor) were actually slightly more stable (by $0.11 \mathrm{kcal} / \mathrm{mol}$ ) than the corresponding duplexes with A-U pairs. Duplexes with 7DA.U pairs on the $3^{\prime}$ terminal end (with 7DA at the $3^{\prime}$ end of the strand with a $5^{\prime}$ neighbor) were, on average, $0.26 \mathrm{kcal} / \mathrm{mol}$ less stable than the corresponding duplexes with A-U pairs. Compared to the predicted values for a duplex with a corresponding A-U pair, the duplex that contained a terminal $5^{\prime}-\mathrm{CU}^{\mathrm{G} 7}{ }^{-3}$ combination showed the greatest decrease in stability, and the duplex that contained a terminal $5^{\prime}-{ }_{\mathrm{UA}}^{7 \mathrm{U}}-3^{\prime} \mathrm{com}-$ bination showed the greatest increase in stability. The trend that the duplexes containing terminal 7DA.U pairs on the $3^{\prime}$ end were on average less stable than duplexes with A-U pairs, while those on the $5^{\prime}$ end were on average more stable, supports the idea of less favorable stacking of the 7 position of 7DA with its $5^{\prime}$ neighbor.

The derived nearest-neighbor parameters listed in Table 3 are consistent with this difference in stacking. In nearestneighbor parameters consisting of a $5^{\prime}$ 7DA pair and a $3^{\prime}$ Watson-Crick pair, the average nearest-neighbor contribution to duplex stability $(-1.56 \mathrm{kcal} / \mathrm{mol})$ is almost equivalent to the corresponding A- $\mathrm{U}$ nearest-neighbor contribution $(-1.59 \mathrm{kcal} / \mathrm{mol})$. However, in nearest-neighbor parameters consisting of a $5^{\prime}$ Watson-Crick pair and a $3^{\prime} 7 \mathrm{DA}$ pair, the average nearest-neighbor contribution to duplex stability $(-1.28 \mathrm{kcal} / \mathrm{mol})$ is less stabilizing than the corresponding A-U nearest-neighbor contribution $(-1.68 \mathrm{kcal} / \mathrm{mol})$.

Comparisons can also be made between duplexes containing internal 7DA.U pairs and terminal 7DA.U pairs. The duplexes containing internal $7 \mathrm{DA} \cdot \mathrm{U}$ pairs are on average $0.43 \mathrm{kcal} / \mathrm{mol}$ less stable than the same duplexes containing A-U pairs, and duplexes containing terminal 7DA.U pairs are on average $0.07 \mathrm{kcal} / \mathrm{mol}$ less stable than the same duplexes containing A-U pairs (Table 2). Interestingly, a similar finding was seen for I.U pairs where internal $\mathrm{I} \cdot \mathrm{U}$ pairs were less stable than their A-U counterparts, and terminal I.U pairs were more stable than their
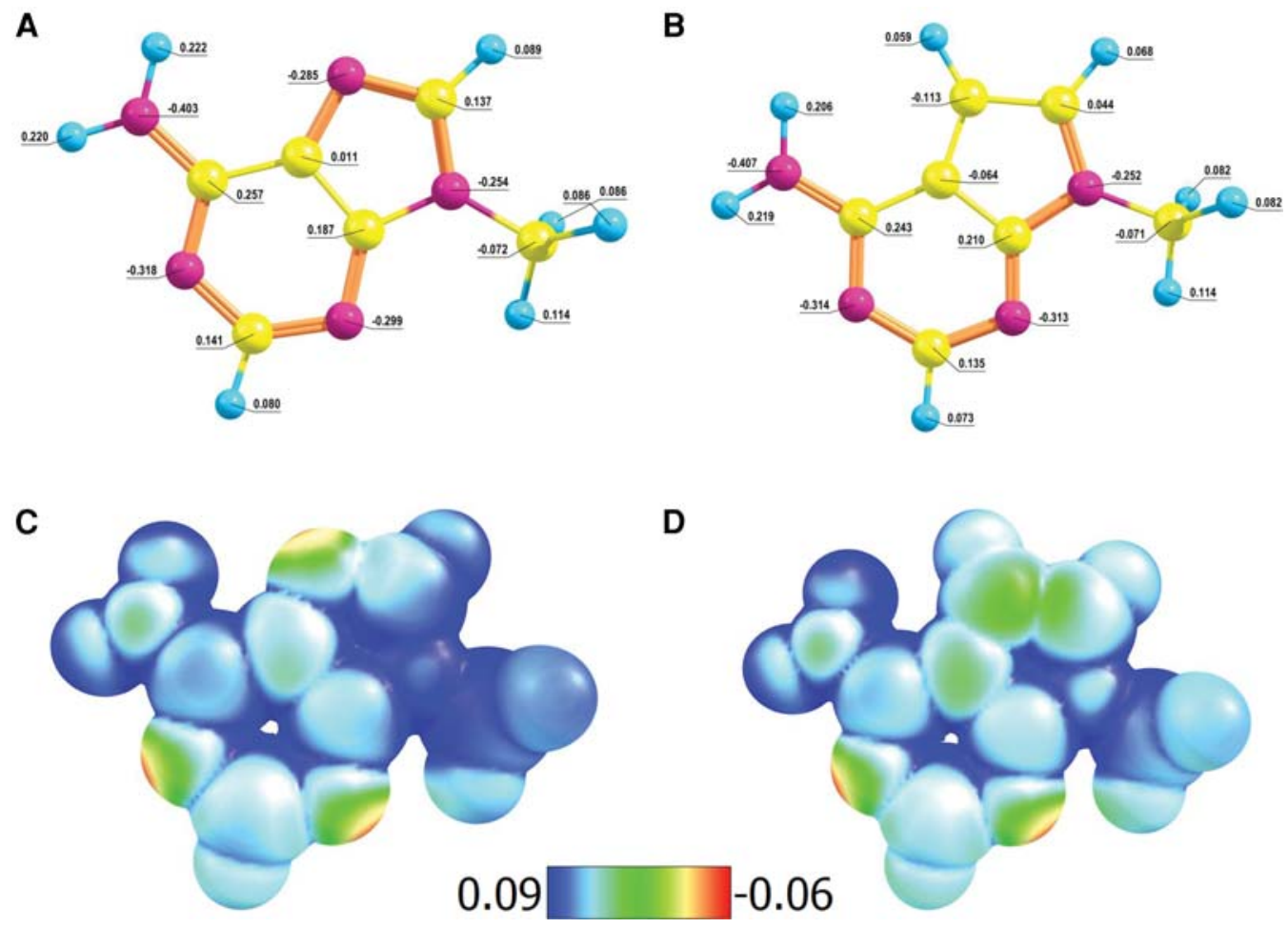

FIGURE 2. Computed Mulliken charges $(A, B)$ and electrostatic potential maps $(C, D)$ for adenosine and 7DA, respectively. 

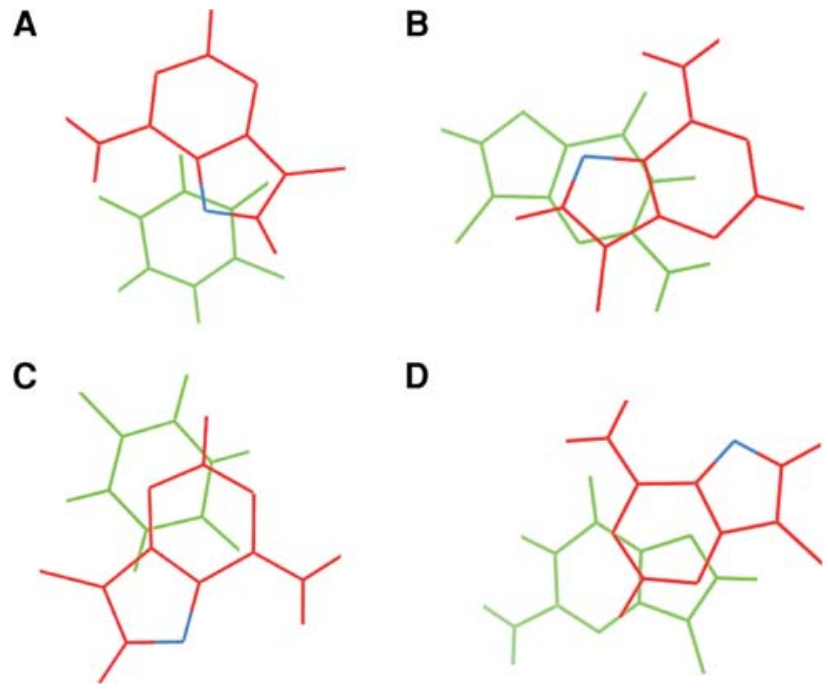

FIGURE 3. The ability of the C7 (blue) on 7DA (red) to impact stacking interactions is likely decided by the positioning $\left(5^{\prime}\right.$ or $\left.3^{\prime}\right)$ of the 7DA relative to the adjacent base (green). Stacks are shown as follows: $(A) 5^{\prime}$ U7-3'; (B) 5'-G7-3'; (C) 5'-7U-3'; and (D) 5'-7G-3'. These stacks were generated using InsightII (Accelrys) for standard A-form geometries and PyMOL (The PyMOL Molecular Graphics System, Version 1.7.4, Schrödinger) for visualization.

A-U counterparts (Wright et al. 2007). The flexibility of the helix termini, increased breathing of terminal base pairs, and the extensive solvation of terminal base pairs may play a role when comparing internal modifications to terminal modifications.

\section{Biochemical impact}

The newly derived thermodynamic parameters can be used to calculate the stability of duplexes in which nonconsecutive 7DA.U pairs have been incorporated. For example, the stability of $\left(\begin{array}{c}\text { GCA7CGC } \\ \text { CGUUGCG }\end{array}\right)$ would be calculated using the previously determined Watson-Crick nearest neighbors (Xia et al. 1998) and the new 7DA nearest neighbors in Table 3 as follows:

$$
\begin{aligned}
& \Delta G_{37}^{\circ}\left(\begin{array}{c}
\text { GCA7CGC } \\
\text { CGUUGCG }
\end{array}\right)=\Delta G_{37, i}^{\circ}+\Delta G_{37}^{\circ}\left(\begin{array}{c}
\text { GC } \\
\text { CG }
\end{array}\right) \\
&+\Delta G_{37}^{\circ}\left(\begin{array}{c}
\mathrm{CA} \\
\mathrm{GU}
\end{array}\right)+\Delta G_{37}^{\circ}\left(\begin{array}{c}
\mathrm{A} 7 \\
\mathrm{UU}
\end{array}\right) \\
&+\Delta G_{37}^{\circ}\left(\begin{array}{c}
7 \mathrm{C} \\
\mathrm{UG}
\end{array}\right)+\Delta G_{37}^{\circ}\left(\begin{array}{c}
\mathrm{CG} \\
\mathrm{GC}
\end{array}\right)+\Delta G_{37}^{\circ}\left(\begin{array}{c}
\mathrm{GC} \\
\mathrm{CG}
\end{array}\right), \\
& \Delta G_{37}^{\circ}\left(\begin{array}{c}
\text { GCA7CGC } \\
\text { CGUUGCG }
\end{array}\right)= 4.09+(-3.42)+(-2.11)+(-0.59) \\
&+(-2.10)+(-2.36)+(-3.42) \\
&=-9.91 \mathrm{kcal} / \mathrm{mol} .
\end{aligned}
$$

Similarly, the stability of a duplex with a terminal 7DA.U pair, such as $\left(\begin{array}{l}\text { GCGCA7 } \\ \text { CGCGUU }\end{array}\right)$ would be calculated as follows:

$$
\begin{aligned}
& \Delta G_{37}^{\circ}\left(\begin{array}{c}
\text { GCGCA7 } \\
\text { CGCGUU }
\end{array}\right)=\Delta G_{37, i}^{\circ}+\Delta G_{37}^{\circ}\left(\begin{array}{c}
\mathrm{GC} \\
\mathrm{CG}
\end{array}\right) \\
&+\Delta G_{37}^{\circ}\left(\begin{array}{c}
\mathrm{CG} \\
\mathrm{GC}
\end{array}\right)+\Delta G_{37}^{\circ}\left(\begin{array}{c}
\mathrm{GC} \\
\mathrm{CG}
\end{array}\right) \\
&+\Delta G_{37}^{\circ}\left(\begin{array}{c}
\mathrm{CA} \\
\mathrm{GU}
\end{array}\right)+\Delta G_{37}^{\circ}\left(\begin{array}{c}
\mathrm{A} 7 \\
\mathrm{UU}
\end{array}\right)+\Delta G_{37, \text { terminal 7U},}^{\circ} \\
& \Delta G_{37}^{\circ}\left(\begin{array}{c}
\text { GCGCA7 } \\
\text { CGCGUU }
\end{array}\right)= 4.09+(-3.42)+(-2.36)+(-3.42) \\
&+(-2.11)+(-0.59)+0.31 \\
&=-7.50 \mathrm{kcal} / \mathrm{mol} .
\end{aligned}
$$

The results of this study indicate that the substitution of a carbon in the N7 position of an internal A leads to a destabilization of the RNA duplex. Under the standard conditions for optical melting experiments, RNA duplexes containing 7DA.U pairs are, on average, less stable than duplexes with corresponding A-U pairs, with some variability based on the nearest neighbors and placement within the duplex. Additional studies are required to further shed light on the stabilizing and destabilizing effects of the incorporation of 7DA into RNA strands.

\section{MATERIALS AND METHODS}

\section{Sequence design and purification}

RNA sequences were designed to create duplexes containing internal and terminal 7DA.U pairs with all possible combinations of nearest neighbors. To prevent fraying at the ends and misalignment, the 7DA.U pairs and adjacent base pairs were placed within a G-C rich stem sequence. Structure prediction software, RNAstructure (Mathews et al. 2004), was used to estimate the stability of the designed duplexes. Since RNAstructure does not accommodate 7DA, A was used in its place. The desired internal duplexes were $\geq 3.9$ $\mathrm{kcal} / \mathrm{mol}$ more stable than the second most stable conformation. As a result, we assumed that there would be little competition with alternate pairing. Oligonucleotides containing 7DA were ordered from the Keck Lab at Yale University, and the complementary strands containing only standard nucleotides were ordered from Integrated DNA Technologies. Purification using Waters Sep-Pak C18 cartridges and preparative thin layer chromatography was performed using standard procedures previously described (Wright et al. 2007).

\section{Duplex formation and optical melting experiments}

To determine the single-strand concentrations of the RNA using Beer's Law, high temperature absorbance readings at $280 \mathrm{~nm}$ and $80^{\circ} \mathrm{C}$ were obtained. Extinction coefficients for each strand were determined using the application RNACalc (McDowell and Turner 1996), with A used in place of 7DA. Equal moles of complementary single strands of RNA were combined to form the duplex. This approximation has been used previously in the literature by our laboratory for optical melting experiments with other nonstandard nucleotides (Wright et al. 2007; Hudson et al. 2013). This approximation has also been used previously (Kowal et al. 2011; Mizrahi 
et al. 2012) to determine the concentration of an oligomer containing 7DA. Even if this approximation results in small deviations from 1:1 mixing, the effect in mixing on thermodynamics derived from optical melting experiments has been found to be small up to $50 \%$ excess of one strand (Peritz et al. 1991; Xia et al. 1998). The total concentration of each duplex was determined by taking a high temperature absorbance reading and using the average of the extinction coefficients of the individual strands. An appropriate volume of sample was dried down and reconstituted in $100 \mu \mathrm{L}$ of melt buffer $(1$ $\mathrm{M} \mathrm{NaCl}, 20 \mathrm{mM}$ sodium cacodylate, $0.5 \mathrm{mM}$ disodium EDTA at $\mathrm{pH}$ 7.0 ) so that the maximum absorbance in a $0.1-\mathrm{cm}$ path length $\mathrm{cu}-$ vette would be $\sim 2$ absorbance units. Optical melting experiments were performed on a Beckman-Coulter DU800 spectrometer with a temperature controller using a heating rate of $1^{\circ} \mathrm{C} / \mathrm{min}$ from $10^{\circ}$ $\mathrm{C}$ to $90^{\circ} \mathrm{C}$ at $280 \mathrm{~nm}$. Each duplex was diluted and tested at nine or more different concentrations that covered a RNA concentration range of $\sim 50$-fold.

\section{Data analysis}

The sigmoidal-shaped curves obtained from the melting experiments were analyzed using MeltWin software (McDowell and Turner 1996) which fits the curves to a two-state model and plots the reciprocal of the melting temperature $\left(T_{\mathrm{M}}\right)$ versus the concentration $\left(C_{\mathrm{T}}\right)$ according to the following equation:

$$
T_{\mathrm{M}}=\left(\frac{2.303 R}{\Delta H^{\circ}}\right) \log \left(\frac{C_{\mathrm{T}}}{4}\right)+\left(\frac{\Delta S^{\circ}}{\Delta H^{\circ}}\right)
$$

In order to calculate the concentration of the duplex from the high temperature absorbance reading and extinction coefficients, MeltWin requires input of the sequence. When sequence information was entered into MeltWin, 7DA was entered as A since MeltWin does not recognize 7DA. The change in Gibbs free energy at $37^{\circ} \mathrm{C}$ was calculated according to the following equation:

$$
\Delta G_{37}^{\circ}=\Delta H^{\circ}-(310.15 K) \Delta S^{\circ} .
$$

Since values obtained from the fitting of melt curves and from the van't Hoff plots of $T_{\mathrm{M}}$ versus $C_{\mathrm{T}}$ were in good agreement, only values from the van't Hoff plots were used for later analysis. The use of the van't Hoff analysis for the determination of nearest-neighbor parameters is standard practice (Xia et al. 1998).

\section{Derivation of nearest-neighbor parameters for $7 \mathrm{DA} \cdot \mathrm{U}$ pairs}

The thermodynamic contribution of 7DA. $U$ pairs was isolated from the total RNA duplex contribution by using the nearest-neighbor model. The total change in Gibbs free energy of each duplex can be written as the sum of contributions of all nearest neighbors:

$$
\begin{aligned}
\Delta G_{37}^{\circ}\left(\begin{array}{c}
\text { CGA7AGC } \\
\text { GCUUUCG }
\end{array}\right)= & \Delta G_{37, i}^{\circ}+\Delta G_{37}^{\circ}\left(\begin{array}{c}
\mathrm{CG} \\
\mathrm{GC}
\end{array}\right)+\Delta G_{37}^{\circ}\left(\begin{array}{c}
\mathrm{GA} \\
\mathrm{CU}
\end{array}\right) \\
& +\Delta G_{37}^{\circ}\left(\begin{array}{c}
\mathrm{A} 7 \\
\mathrm{UU}
\end{array}\right)+\Delta G_{37}^{\circ}\left(\begin{array}{c}
7 \mathrm{~A} \\
\mathrm{UU}
\end{array}\right) \\
& +\Delta G_{37}^{\circ}\left(\begin{array}{c}
\mathrm{AG} \\
\mathrm{UC}
\end{array}\right)+\Delta G_{37}^{\circ}\left(\begin{array}{c}
\mathrm{GC} \\
\mathrm{CG}
\end{array}\right)
\end{aligned}
$$

where $\Delta G_{37}^{\circ}\left(\begin{array}{c}\text { CGA7AGC } \\ \text { GCUUUCG }\end{array}\right)$ is the measured free energy change associated with the duplex, $\Delta G_{37, i}^{\circ}$ is the free energy penalty for duplex initiation $(4.09 \mathrm{kcal} / \mathrm{mol})$, and all other parameters are the individual nearest-neighbor free energy contributions (Xia et al. 1998). This equation was rearranged to isolate the 7DA.U nearest-neighbor contributions:

$$
\begin{array}{r}
\text { 7DA } \cdot \mathrm{U} \text { Contributions }=\Delta G_{37}^{\circ}\left(\begin{array}{c}
\mathrm{A} 7 \\
\mathrm{UU}
\end{array}\right)+\Delta G_{37}^{\circ}\left(\begin{array}{c}
7 \mathrm{~A} \\
\mathrm{UU}
\end{array}\right) \\
=\Delta G_{37}^{\circ}\left(\begin{array}{c}
\mathrm{CGA7AGC} \\
\mathrm{GCUUUCG}
\end{array}\right)-\Delta G_{37, i}^{\circ}-\Delta G_{37}^{\circ}\left(\begin{array}{c}
\mathrm{CG} \\
\mathrm{GC}
\end{array}\right) \\
-\Delta G_{37}^{\circ}\left(\begin{array}{c}
\mathrm{GA} \\
\mathrm{CU}
\end{array}\right)-\Delta G_{37}^{\circ}\left(\begin{array}{c}
\mathrm{AG} \\
\mathrm{UC}
\end{array}\right)-\Delta G_{37}^{\circ}\left(\begin{array}{c}
\mathrm{GC} \\
\mathrm{CG}
\end{array}\right)
\end{array}
$$

Duplexes with internal 7DA.U pairs contained contributions from two 7DA.U nearest-neighbor parameters, while duplexes containing terminal 7DA.U pairs only contained one 7DA.U nearest-neighbor parameter. Equations 7 and 8 can also be written for $\Delta H^{\circ}$ and $\Delta S^{\circ}$ to determine the 7DA.U nearest-neighbor enthalpy and entropy contributions. The resulting 7DA.U thermodynamic contributions were assembled into a matrix in Microsoft Excel and the LINEST function was used to perform linear regression. The eight possible 7DA.U nearest-neighbor combinations and a terminal 7DA.U parameter were used as variables and were fit to the $7 \mathrm{DA} \cdot \mathrm{U}$ contributions described in Equation 8. The linear regression function solved for each variable and yielded eight linearly independent 7DA.U nearest-neighbor parameters, as well as a penalty for a terminal 7DA.U pair.

\section{Computational analysis}

The geometry for adenosine was obtained from InsightII (Accelrys). The ribose sugar was substituted for a methyl group, and the positions of the $\mathrm{N}-\mathrm{CH}_{3}$ bond on both base pairs and the $\mathrm{C}-\mathrm{H}$ group at the 7 position of 7DA were optimized at the MP2(full)/6-311G** level of theory using Gaussian 09 (Frisch et al. 2009) while the rest of the RNA base atoms were constrained to their InsightII position. The electrostatic potential maps of adenosine and 7DA were generated using the Psi4 computational package (Turney et al. 2012). Electrostatic potential values were calculated from the frozen core density fitting MP2 method, 6-311++G** basis sets, and aug-cc-pvtz-ri density fitting basis sets. The cube file was imported into Chemcraft (Chemcraft, Version 1.7 [build 375], Zhurko), and the diagram was created by painting the potential values on the van der Waals spheres.

\section{SUPPLEMENTAL MATERIAL}

Supplemental material is available for this article.

\section{ACKNOWLEDGMENTS}

This work was supported by the National Institutes of Health (2R15GM085699-02).

Received November 30, 2015; accepted March 21, 2016. 


\section{REFERENCES}

Acs G, Reich E, Mori M. 1964. Biological and biochemical properties of the analogue antibiotic tubercidin. Proc Natl Acad Sci 52: 493-501.

Anzai K, Nakamura G, Suzuki S. 1957. A new antibiotic, tubercidin. J Antibiot 10: 201-204.

Biabani MF, Gunasekera SP, Longley RE, Wright AE, Pomponi SA. 2002. Tubercidin, a cytotoxic agent from the marine sponge Caulospongia biflabellata. Pharm Biol 40: 302-303.

Bloch A, Leonard RJ, Nichol CA. 1967. On the mode of action of 7 deaza-adenosine (tubercidin). Biochim Biophys Acta 138: 10-25.

Cantara WA, Crain PF, Rozenski J, McCloskey JA, Harris KA, Zhang X, Vendeix FAP, Fabris D, Agris PF. 2011. The RNA modification database, RNAMDB: 2011 update. Nucleic Acids Res 39: D195-D201.

Charette M, Gray MW. 2000. Pseudouridine in RNA: what, where, how, and why. IUBMB Life 49: 341-351.

Dominguez-Martin A, Choquesillo-Lazarte D, Dobado JA, Vidal I, Lezama L, Gonzalez-Perez JM, Castineiras A, Niclos-Gutierrez J. 2013. From 7-azaindole to adenine: molecular recognition aspects on mixed-ligand $\mathrm{Cu}(\mathrm{II})$ complexes with deaza-adenine ligands. Dalton Trans 42: 6119-6130.

Frisch MJ, Trucks GW, Schlegel HB, Scuseria GE, Robb MA, Cheeseman JR, Scalmani G, Barone V, Mennucci B, Petersson GA, et al. 2009. Gaussian 09, revision A.1. Gaussian, Inc., Wallingford, CT.

Hudson GA, Bloomingdale RJ, Znosko BM. 2013. Thermodynamic contribution and nearest-neighbor parameters of pseudouridineadenosine base pairs in oligoribonucleotides. RNA 19: 1474-1482.

Kowal EA, Ganguly M, Pallan PS, Marky LA, Gold B, Egli M, Stone MP. 2011. Altering the electrostatic potential in the major groove: thermodynamic and structural characterization of 7-deaza$2^{\prime}$-deoxyadenosine:dT base pairing in DNA. J Phys Chem B 115: 13925-13934.

Kurogi Y, Matsuo Y, Mihara Y, Yagi H, Shigaki-Miyamoto K, Toyota S, Azuma Y, Igarashi M, Tani T. 2014. Identification of a chemical inhibitor for nuclear speckle formation: implications for the function of nuclear speckles in regulation of alternative pre-mRNA splicing. Biochem Biophys Res Commun 446: 119-124.

Mathews DH, Sabina J, Zuker M, Turner DH. 1999. Expanded sequence dependence of thermodynamic parameters improves prediction of RNA secondary structure. J Mol Biol 288: 911-940.

Mathews DH, Disney MD, Childs JL, Schroeder SJ, Zuker M, Turner DH. 2004. Incorporating chemical modification constraints into a dynamic programming algorithm for prediction of RNA secondary structure. Proc Natl Acad Sci USA 101: 7287-7292.

McDowell JA, Turner DH. 1996. Investigation of the structural basis for thermodynamic stabilities of tandem GU mismatches: Solution structure of (rGAGGUCUC) ${ }_{2}$ by two-dimensional NMR and simulated annealing. Biochemistry 35: 14077-14089.

Mizrahi RA, Phelps KJ, Ching AY, Beal PA. 2012. Nucleoside analog studies indicate mechanistic differences between RNA-editing adenosine deaminases. Nucleic Acids Res 40: 9825-9835.

Ojha RP, Sanyal NK. 1991. Biological activity of 7-deazaadenine nucleoside antibiotics: a theoretical study. J Mol Struct: THEOCHEM 79: 275-291.

Olsen DB, Eldrup AB, Bartholomew L, Bhat B, Bosserman MR, Ceccacci A, Colwell LF, Fay JF, Flores OA, Getty KL, et al. 2004. A 7-deaza-adenosine analog is a potent and selective inhibitor of hepatitis $C$ virus replication with excellent pharmacokinetic properties. Antimicrob Agents Chemother 48: 3944-3953.

Owen SP, Smith CG. 1964. Cytotoxicity and antitumor properties of the abnormal nucleoside tubercidin. Cancer Chemother Rep 36: 19-22.

Peritz AE, Kierzek R, Sugimoto N, Turner DH. 1991. Thermodynamic study of internal loops in oligoribonucleotides: symmetric loops are more stable than assymetric loops. Biochemistry 30: 6428-6436.

Schroeder SJ, Turner DH. 2009. Optical melting measurements of nucleic acid thermodynamics. In Methods in Enzymology (ed. Herschlag D), Vol. 468, pp. 371-387. Academic Press, Burlington, MA.

Shi Y-Z, Wu Y-Y, Wang F-H, Tan Z-J. 2014. RNA structure prediction: progress and perspective. Chin Phys B 23: 078701.

Turney JM, Simmonett AC, Parrish RM, Hohenstein EG, Evangelista FA, Fermann JT, Mintz BJ, Burns LA, Wilke JJ, Abrams ML, et al. 2012. PSI4: an open-source ab initio electronic structure program. Wiley Interdiscip Rev: Comput Mol Sci 2: 556-565.

Vittori S, Dal Ben D, Lambertucci C, Marucci G, Volpini R, Cristalli G. 2006. Antiviral properties of deazaadenine nucleoside derivatives. Curr Med Chem 13: 3529-3552.

Wright DJ, Rice JL, Yanker DM, Znosko BM. 2007. Nearest neighbor parameters for Inosine-Uridine pairs in RNA duplexes. Biochemistry 46: 4625-4634.

Xia TB, SantaLucia J, Burkard ME, Kierzek R, Schroeder SJ, Jiao XQ, Cox C, Turner DH. 1998. Thermodynamic parameters for an expanded nearest-neighbor model for formation of RNA duplexes with Watson-Crick base pairs. Biochemistry 37: 14719-14735. 

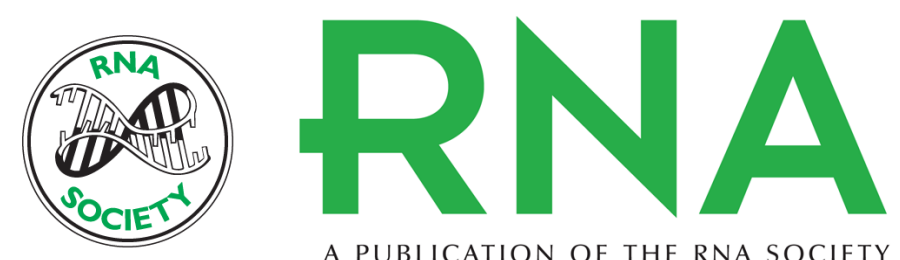

A PUBLICATION OF THE RNA SOCIETY

\section{Nearest-neighbor parameters for 7-deaza-adenosine-uridine base pairs in RNA duplexes}

Katherine E. Richardson and Brent M. Znosko

RNA 2016 22: 934-942 originally published online April 20, 2016

Access the most recent version at doi:10.1261/rna.055277.115

\section{Supplemental http://rnajournal.cshlp.org/content/suppl/2016/04/19/rna.055277.115.DC1 Material}

References This article cites 24 articles, 4 of which can be accessed free at: http://rnajournal.cshlp.org/content/22/6/934.full.html\#ref-list-1

Creative This article is distributed exclusively by the RNA Society for the first 12 months after the Commons License full-issue publication date (see http://rnajournal.cshlp.org/site/misc/terms.xhtml). After 12 months, it is available under a Creative Commons License (Attribution-NonCommercial 4.0 International), as described at http://creativecommons.org/licenses/by-nc/4.0/.

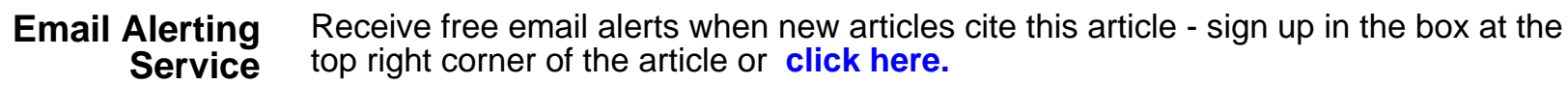

